Белгородский государственный технологический университет им. В. Г. Шухова, г. Белгорд, e-mail:taem.masa@gmail.com

ЧИЖОВ СЕРГЕЙ ФЕДРОВИЧ

к.э.н., доцент, Институт экономики и менеджмента, Белгородский государственный технологический университет им. В. Г. Шухова, г. Белгорд, e-mail:chijov@intbel.ru

\title{
ОЦЕНКА РИСКОВ ПОАПИСКИ В СТРАХОВЫХ КОМПАНИЯХ
}

Аннотауия. Цель работы. В статье рассматриваются риски подписки в страховых компаниях, предложив модель, совместимую с характером страхового рынка, которая состоит из отдельных научных и бухгалтерских показателей для оценки деятельности страховых компаний, степени риска андеррайтинга и возможности прогнозирования будущих рисков. Метод. Проведен статистический анализ изменений предложенной модели для оценки рисков подписки, которая состоит из нескольких показателей оченки, после применения ее к страховым компаниям (6 компаний) и использования финансовой отчетности этих компаний за период 2013-2017 г2. В глобальном масштабе, если соотношение рассчитывается в приемлемом диапазоне, это означает, что показатели компании хорошие и прибыльные, Они не подвержены будущим рискам, связанным с деятельностью IPO, и наоборот, если коэффициент находится за пределами международно

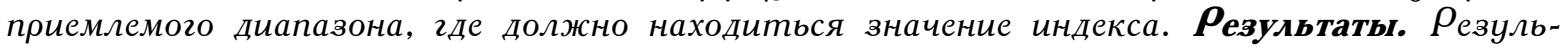
таты исследования показали способность этой модели в количественных показателях оценивать результаты деятельности компаний, помогать в развитии управления рисками страховых компаний, а также выявлять сильные и слабые стороны частного

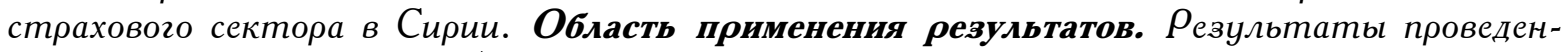
ного исследования могут быть использованы при анализе и прогнозировании изменений риска подписки в страховых компаниях. Выводы. Делается вывод, что предложенная модель помогает прогнозировать риск андеррайтинга и принимать своевременные меры со стороны ответственного органа.

Ключевые слова: оценка рисков, риск андеррайтинга, страховые компании, риск, индикаторы, модель.

AL QAISI RAMZAN YOUSSEF graduate student, Institute of Economics and management, Belgorod state technological University University. V. G. Shukhov, Belgorod, e-mail:taem.masa@gmail.com

CHIZHOV SERGEY FEDOROVICH

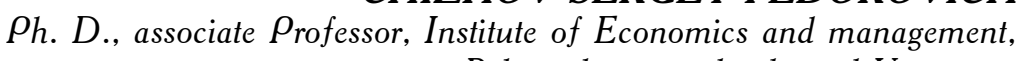
Belgorod state technological University University. V. G. Shukhov, Belgorod, e-mail:chijov@intbel.ru

\section{ASSESSMENT OF SUBSCRIPTION RISKS IN INSURANCE COMPANIES}

Abstract. $\boldsymbol{\rho}_{\text {urpose of }}$ work. The article discusses the risks of subscription in insurance companies, offering a model compatible with the nature of the insurance market, which consists of separate scientific and accounting indicators to assess the activities of insurance companies, the degree 
of underwriting risk and the possibility of forecasting future risks. Method. A statistical analysis of changes in the proposed model for assessing the risks of subscription, which consists of several evaluation indicators, after its application to insurance companies (6 companies) and the use of financial statements of these companies for the period 2013-2017. Globally, if the ratio is calculated in an acceptable range, it means that the company's performance is good and profitable, they are not exposed to future risks associated with $I P O$ activities, and Vice versa, if the ratio is outside the internationally acceptable range, where the index value should be. Results. The results of the study showed the ability of this model to quantify the performance of companies, to help in the development of risk management of insurance companies, as well as to identify the strengths and weaknesses of the private insurance sector in Syria. The scope of the results. The results of the study can be used in the analysis and forecasting of changes in subscription risk in insurance companies. Summary. It is concluded that the proposed model helps to predict the risk of underwriting and take timely action by the responsible authority.

Keywords: risk assessment, underwriting risk, insurance companies, risk, indicators, model.

Введение. С позиции риск-менеджмента под источниками риска следует понимать деятельность, которая в общем случае для страховых компаний делится на инвестиционную и страховую [1]. И страховые компании работают в нестабильной среде, а страховые рынки, как правило, в отсутствие систем надзора и контроля склонны к неконтролируемой конкуренции, когда страховые компании выполняют свои обязательства, не следуя неправильной практике. Все страховые компании и учреждения по всему миру подлежат надзору и контролю со стороны государственных органов. Соответственно, первой функцией регулирующего органа является необходимость установить, что страховая компания должным образом осуществляет свою деятельность [3]. На страховую деятельность также оказывает серьезное воздействие внутренняя среда. Успешность страховой деятельности с учетом опыта построения моделей банкротства банков, вероятно, будет различаться в зависимости от региона [2]. Следовательно, важность этого исследования заключается в том, чтобы предоставить модель для оценки рисков подписки в страховых компаниях, чтобы помочь регулирующим органам узнать статус страховых компаний и своевременно принять соответствующие меры.

Методы исследования. Статистическая группа исследования - частные страховые компании, работающие на страховом рынке Сирии Выборка исследования включает 6 страховых компаний, и они показаны в табл.1. ниже.

Таблийа 1

Изученные страховые компании*

\begin{tabular}{|c|c|c|c|c|c|c|}
\hline $\begin{array}{c}\text { Страховые } \\
\text { компании }\end{array}$ & $\begin{array}{c}\text { Объединенная } \\
\text { компания }\end{array}$ & $\begin{array}{c}\text { Кооператив } \\
\text { Юнион Компани }\end{array}$ & $\begin{array}{c}\text { Национальная } \\
\text { компания }\end{array}$ & $\begin{array}{c}\text { Сирийская } \\
\text { международная } \\
\text { компания }\end{array}$ & $\begin{array}{c}\text { Арабская } \\
\text { Ориент } \\
\text { Компания }\end{array}$ & $\begin{array}{c}\text { Компания Al } \\
\text { Aqеelah }\end{array}$ \\
\hline Код компании & UIC & SAIC & NIC & AROP & AOIC & ATI \\
\hline
\end{tabular}

*Источник: подготовка исследователя на сайте Управления страхового надзора [4].

Предложенная модель будет использоваться для оценки рисков подписки, которая состоит из нескольких показателей оценки, после применения ее к страховым компаниям (6 компаний) и использования финансовой отчетности этих компаний за период 2013-2017 гг. В глобальном масштабе, если соотношение рассчитывается в приемлемом диапазоне, это означает, что показатели компании хорошие и прибыльные. Они не подвержены будущим рискам, связанным с деятельностью IPO, и наоборот, если коэффициент находится за пределами международно приемлемого диапазона, где значение индекса должно находиться в приемлемом диапазоне $[5]$.

В следующей табл. 2 приведены показатели этой модели для оценки рисков IPO и международно признанных лимитов. 
АЛ КАИССИ РАЗАН ЮССЕФ, ЧИЖОВ С.Ф.

ОЦЕНКА РИСКОВ ПОДПИСКИ В СТРАХОВЫХ КОМПАНИЯХ

Таблица 2

Показатели модели оценки риска и допустимые пределы*

\begin{tabular}{|c|c|c|}
\hline Предлагаемые модельные показатели & Математическое соотношение показателей & $\begin{array}{c}\text { Универсально } \\
\text { приемлемый домен }\end{array}$ \\
\hline Уровень технических потерь & $L R_{t}=\frac{L I_{t}}{E P_{t}} \times 100$ & $\begin{array}{c}\text { Расположен между } \\
28 \% \text { до } 80 \%\end{array}$ \\
\hline Ставка маржи подписной прибыли & $U P M_{t}=1-\left(\frac{L I_{t}}{E P_{t}}+\frac{E I_{t}}{W P_{G r o s s}}\right)$ & $\begin{array}{c}\text { Расположен между } \\
3 \% \text { до } 15 \%\end{array}$ \\
\hline Процентное изменение в излишках & $\Delta S=\left(\frac{\bar{S}_{t}}{\bar{S}_{t-1}}-1\right) \times 100$ & $\begin{array}{c}\text { Расположен между } \\
10 \% \text { до }+50 \%\end{array}$ \\
\hline
\end{tabular}

*Источник: подготовлено исследователем на основе [7, 11].

Уровень технических потерь. Этот индикатор измеряет процент компенсации нагрузки в любой год $\left(L I_{t}\right)$, в течение финансового периода после внесения корректировок в отношении обрабатываемых претензий. Разделенные на премии, заработанные за тот же год $\left(E P_{t}\right)$. Коэффициент технических потерь $\left(L R_{t}\right)$ определяется на основе приведенного выше определения[11]:

$$
\begin{gathered}
L R_{t}=\frac{L I_{t}}{E P_{t}} \times 100 \\
L R_{t}=\left(\frac{L_{t}+\Delta \operatorname{Res}_{t}}{W P_{\text {Net }_{t}}+\Delta \operatorname{Res}_{\text {unx }}}\right) \times 100
\end{gathered}
$$

Приемлемый уровень потерь колеблется от $28 \%$ до $60 \%$ и является международно приемлемым, даже если он достигает $70 \%$ или $80 \%$. Коэффициент убыточности является одним из критериев эффективности деятельности страховых компаний, который способствует оценке результатов подписки и принятию страховых решений, является средством определения тарифов страхования и проверки степени их справедливости [13]. Он также используется для оценки надежности финансовых центров страховых компаний. Уровень потерь варьируется от года к году в зависимости от изменения стоимости компенсации и суммы заработанных премий [8].

Ставка маржи подписной прибыли. Учитывая уровень прибыли подписки ( $\left.U P M_{t}\right)$ по следующей формуле [12]:

$$
U P M_{t}=1-\left(\frac{L I_{t}}{E P_{t}}+\frac{E I_{t}}{W P_{\text {Grosst }}}\right)
$$

нет согласованного минимального или более высокого порога для маржинальной подписки, однако можно сказать, что допустимая маржа составляет от $3 \%$ до $10 \%$, основываясь на предыдущих исследованиях в этой области [14]. Даже если он вырос до 12\%, или на 15\% из-за отсутствия катастрофы и негативных изменений [6].

Процентное изменение в излишках. Этот показатель отражает скорость изменения размера скорректированного профицита в любом году по сравнению со средним профицитом в предыдущем году. Изменение профицита $(\stackrel{\Delta S)}{ }$ рассчитывается в соответствии с теоретическим определением [9]:

$$
\Delta S=\left(\frac{\bar{S}_{t}}{\bar{S}_{t-1}}-1\right) \times 100,
$$


где $\bar{S}_{t}$-скорректированный профицит в году $t ; \bar{S}_{t-1}$ - скорректированный профицит в году $\mathrm{t}-1$.

Приемлемый диапазон этого соотношения колеблется от $-10 \%$ до $+50 \%$.

Результаты в соответствии с применением индикаторов предлагаемой модели для оценки рисков подписки, перечисленных в табл. 2 выше, применительно к сирийским страховым компаниям. В табл. 3 ниже показано развитие индексов риска частного сектора за исследуемый период.

Таблица 3

Разработка показателей риски подписки для частных страховых компаний за период 2013-2017 гг. (\%)*

\begin{tabular}{|c|c|c|c|c|c|c|}
\hline Индикаторы & Год & 2013 & 2014 & 2015 & 2016 & 2017 \\
\hline \multirow{4}{*}{$L R_{t}$} & UIC & 22.835 & 50.291 & 59.701 & 54.526 & 62.760 \\
\cline { 2 - 7 } & SAIC & 23.872 & 41.802 & 33.47 & 42.963 & 41.186 \\
\cline { 2 - 7 } & NIC & 17.407 & 29.238 & 67.297 & 73.143 & 76.828 \\
\cline { 2 - 7 } & AROP & 34.993 & 67.200 & 71.90 & 54.660 & 71.951 \\
\cline { 2 - 7 } & AOIC & 23.178 & 39.868 & 48.931 & 62.683 & 66.791 \\
\cline { 2 - 7 } & ATI & 16.316 & 15.186 & 35.587 & 51.476 & 69.190 \\
\hline \multirow{5}{*}{ URM } & UIC & 61.893 & 33.322 & 25.411 & 32.013 & 26.12 \\
\cline { 2 - 7 } & SAIC & 10.150 & 18.348 & 40.391 & 36.174 & 33.677 \\
\cline { 2 - 7 } & NIC & 66.013 & 52.601 & 10.728 & 14.140 & 11.018 \\
\cline { 2 - 7 } & AROP & -42.001 & 14.401 & 12.058 & 31.77 & 13.333 \\
\cline { 2 - 7 } & AOIC & 20.260 & 23.094 & 12.915 & 9.722 & 1.218 \\
\cline { 2 - 7 } & ATI & 13.776 & -445.411 & 35.208 & 39.437 & 12.251 \\
\hline \multirow{5}{*}{$\Delta S$} & UIC & 8.685 & 4.210 & 0.580 & 6.904 & 4.990 \\
\cline { 2 - 7 } & SAIC & 56.215 & 7.862 & 1.633 & 0.072 & 4.601 \\
\cline { 2 - 7 } & NIC & 14.877 & 16.993 & 4.621 & 1.580 & 2.002 \\
\cline { 2 - 7 } & AROP & 1.265 & 3.156 & 5.773 & 7.038 & 9.791 \\
\cline { 2 - 7 } & AOIC & 45.662 & 8.973 & 9.276 & 12.053 & 4.837 \\
\cline { 2 - 7 } & ATI & 7.554 & 15.872 & -4.797 & 6.580 & -12.800 \\
\hline
\end{tabular}

*Источник: расчеты исследователя на основе годовых отчетов частных страховых компаний [17].

Наблюдая за изменением ставок андеррайтинга, мы отмечаем из таблицы выше, что Объединенной страховой компанией достигнута положительная норма прибыли с небольшими колебаниями в течение периода 2013-2017 гг., которая означает, что Объединенная компания получила прибыль. Таким образом, это означает, что компания заинтересована в самой подписке и работает в соответствии с технической базой подписки [18].

Союз кооперативной компании также добился более высокой маржи, чем границы, и это указывает на способность компании увеличивать хорошие риски в страховом портфеле, чтобы избежать потерь по подписке и тем самым избежать рисков, связанных с ними. Однако индекс остается в допустимых пределах. Волатильность в индексе показывает способность компании избегать нехороших рисков, Потеря подписки может быть выставлена [10]. Это объясняется тем фактом, что Сирийская арабская страховая компания «Ориент» воспользовалась опытом своей дочерней компании «Арабская восточная компания Объединенных Арабских Эмиратов», получившей рейтинг Standard \& Poor's A. [15]. Это позитивно отразится на будущем прогрессе Сирийского арабского машрека на административном и техническом уровнях. В течение 2015 и 2016 гг. страховая компания Al Aqeelah Takaful достигла более высоких, чем ожи- 
далось, ограничений на прибыль от подписки, отражая способность компании увеличивать риски в страховом портфеле, чтобы избежать потери подписки и отсутствия крупных аварий в течение этих двух лет [19].

С точки зрения соотношения изменения в профиците табл. 3 показывает, что оно находится в пределах, приемлемых для Объединенной страховой компании, указывая на то, что в финансовом положении компании нет недостатков, хотя это частная компания на сирийском страховом рынке, и это для них положительный момент [16]. Кроме того, процент изменения в профиците остался в допустимых пределах компании кооперативного союза, но с годами он увеличивался, и это свидетельствует о целостности финансового положения компании и ее соблюдении контроля руководства по подписке [20].

Выводы. Результаты проведенного исследования позволяют сделать следующие выводы:

- Нет существенной разницы в нормах убытков, марже подписной прибыли и процентном изменении в профиците между сирийскими частными страховыми компаниями из-за сходства недавнего опыта на сирийском страховом рынке.

- Исследуемые инвестиционные показатели частных акционерных компаний количественно различаются, а частные компании ограничены некоторыми каналами, которые обеспечивают им только прибыльность.

- Модель, примененная в этом исследовании к страховым компаниям с целью разработки оценки эффективности компаний с точки зрения подверженности риску подписки, доказала свою способность прогнозировать риски, которым могут быть подвержены компаниям, а затем помочь руководству, отвечающему за управление рисками, в разработке и выборе соответствующих и совместимых планов и стратегий. С результатами показателей этой модели.

- Предлагаемая модель, применяемая к страховым компаниям, является предварительной попыткой, которая может быть разработана на основе усилий новых исследователей в этой области в будущем путем увеличения количества показателей этой модели.

Литература

1. Масино, М. Н., Лорионов, А. В. Методика организачии проиесса риск-менеджмента в платежной системе // Управление финансовыми рисками. 2016. № 4. С. 288-297.

2. Белоусова, В. Ю., Козырь, И. О. Как макроэкономические переменные влияют на прибыльность российских банков // Журнал новой экономической ассочиащии. 2016. № 30 (2). C. 72-103. 3. Бартон, Т., Шенкир, У., Уокер, П. Риск-менеджмент. Практика ведущих компаний. - М. : Вильямс, 2008.

4. Сайт сирийского страхового надзора. - URL : http://www.sisc.sy.

5. Pritchett, S. T., Schmit, J. T., Doerpinghaus, H. I. \& Athearn, J. L. Risk management and insurance. - New York: West Publishing Company, 2006. P. 661.

6. Вишняков, Я. Д., Радаев, Н. Н. Общая теория рисков : учеб. пособие для студ. высш. учеб. заведений. - М. : Изд. иентр «Академия», 2007.

7. Дрибати, Я. Аналитическое исследование группового страхования. Эмпирическое исследование страховых компаний. - Сирия, Университет Дамаска. Факультет экономики, 2006.

8. Сплетухов, Ю. А., Дюжсиков, Е. Ф. Страхование : учеб. пособие. - М. : ИНФРА-М, 2004.

9. Abu Bakr, E. Quantitative Model of Determinants of Financial Efficiency in Life Insurance : Study On the Egyptian insurance companies // The Egyptian Journal of Business Studies. - College Commerce, Mansoura University, Egypt. 2006. Vol. 33. No. 1.

10. Бланк, И. А. Управление финансовыми рисками. - М. : Ника-Центр, 2006.

11. Гвозденко, А. А. Основы страхования : учебник. - М. : Финансы и статистика, 2005.

12. Al-Kholy, H. Quantifying the target of the demand for fire insurance branches in light of the determinants related to its achievement in the Egyptian insurance market / Al-Raed Al Arabi. - Damascus, Syria, 2010. No. 107. P. 47.

13. Hamouda, I. The Effect of Type of Property and Type of Insurance on the Profit Margin of Insurance in Property Insurance,. - Alexandria University, Egypt, College of Commerce for Scientific Research, Faculty of Commerce, 2002. Vol. 3.

14. Erekat, H. Aqeel, S. Insurance and Risk Management : Theory and Practice. - Second Edition. - Jordan, Amman : Dar Wael Publishing and Distribution, 2010. P. 49.

15. Editorial Board. Arab Orient Insurance Company receives A rating from Standard \& Poor's // Insurance and Knowledge Magazine. Syrian Insurance Federation, Damascus. 2009. Issue 4. P. 53.

16. Guillen, M. Customer loyalty in the insurance industry : a logistic regression approach // Conference in Actuarial Science and Finance on Samos, Greece. 2002. P. 1-18.

17. Hussein, H. Evaluation of Performance in Algerian Insurance Institutions : Case Study of National Insurance Company // University of Algiers, Faculty of Economic Sciences. 2012. P. 210.

18. .Сайт частных страховых компаний в Сирии. - URL : http://www.sisc.sy/Publications/11/Ar.

19. Khatib, Z. Characteristics of Insurance Contract // Journal of Social Insurance. - Syria, Damascus. 2008. 
No. 11. P. 11-20.

20. Ming, P. Pricing in the Actuarial Market : Ph. D. Dissertation, the Graduate School of the Ohio State University, 2007. P. 1-99. - URL : http://proquest.umi.com.

21. Razok, S. Types and Forms of Insurance / Al-Raed Al-Arabi. - Damascus, Syria : Arab Union for Reinsurance Company. 2012. P. 61.

\section{References:}

1. Masino, M. N., Lorionov, A. V. Metodika organizacii processa risk-menedzhmenta v platezhnoj sisteme // Upravlenie finansovymi riskami. 2016. № 4. S. 288-297.

2. Belousova, V. YU., Kozyr', I. O. Kak makroekonomicheskie peremennye vliyayut na pribyl'nost' rossijskih bankov // ZHurnal novoj ekonomicheskoj associacii. 2016. № 30 (2). S. 72-103. 3. Bar-

ton, T., SHenkir, U., Uoker, P. Risk-menedzhment. Praktika vedushchih kompanij. - M. : Vil'yams, 2008.

4. Sajt sirijskogo strahovogo nadzora. - URL: http://www.sisc.sy.

5. Pritchett, S. T., Schmit, J. T., Doerpinghaus, H. I. \& Athearn, J. L. Risk management and insurance. - New York: West Publishing Company, 2006. P. 661.

6. Vishnyakov, YA. D., Radaev, N. N. Obshchaya teoriya riskov : ucheb. posobie dlya stud. vyssh. ucheb. zavedenij. - M. : Izd. centr «Akademiya», 2007.

7. Dribati, YA. Analiticheskoe issledovanie gruppovogo strahovaniya. Empiricheskoe issledovanie strahovyh kompanij. - Siriya, Universitet Damaska. Fakul'tet ekonomiki, 2006.

8. Spletuhov, YU. A., Dyuzhikov, E. F. Strahovanie : ucheb. posobie. - M. : INFRA-M, 2004.

9. Abu Bakr, E. Quantitative Model of Determinants of Financial Efficiency in Life Insurance : Study On the Egyptian insurance companies // The Egyptian Journal of Business Studies. - College Commerce, Mansoura University, Egypt. 2006. Vol. 33. No. 1.

10. Blank, I. A. Upravlenie finansovymi riskami. - M. : Nika-Centr, 2006.

11. Gvozdenko, A. A. Osnovy strahovaniya : uchebnik. - M. : Finansy i statistika, 2005.

12. Al-Kholy, H. Quantifying the target of the demand for fire insurance branches in light of the determinants related to its achievement in the Egyptian insurance market / Al-Raed Al Arabi. - Damascus, Syria, 2010. No. 107. P. 47.

13. Hamouda, I. The Effect of Type of Property and Type of Insurance on the Profit Margin of Insurance in Property Insurance,. - Alexandria University, Egypt, College of Commerce for Scientific Research, Faculty of Commerce, 2002. Vol. 3.

14. Erekat, H. Aqeel, S. Insurance and Risk Management : Theory and Practice. - Second Edition. - Jordan, Amman : Dar Wael Publishing and Distribution, 2010. P. 49.

15. Editorial Board. Arab Orient Insurance Company receives A rating from Standard \& Poor's // Insurance and Knowledge Magazine. Syrian Insurance Federation, Damascus. 2009. Issue 4. P. 53.

16. Guillen, M. Customer loyalty in the insurance industry : a logistic regression approach // Conference in Actuarial Science and Finance on Samos, Greece. 2002. P. 1-18.

17. Hussein, H. Evaluation of Performance in Algerian Insurance Institutions : Case Study of National Insurance Company // University of Algiers, Faculty of Economic Sciences. 2012. P. 210.

18. .Sajt chastnyh strahovyh kompanij v Sirii. - URL : http://www.sisc.sy/Publications/11/Ar.

19. Khatib, Z. Characteristics of Insurance Contract // Journal of Social Insurance. - Syria, Damascus. 2008. No. 11. P. 11-20.

20. Ming, P. Pricing in the Actuarial Market: Ph. D. Dissertation, the Graduate School of the Ohio State University, 2007. P. 1-99. - URL : http://proquest.umi.com.

21. Razok, S. Types and Forms of Insurance / Al-Raed Al-Arabi. - Damascus, Syria : Arab Union for Reinsurance Company. 2012. P. 61. 